\title{
A tool to improve patient and public engagement in commissioning sexual and reproductive health and HIV services
}

\section{Ava Lorenc, ${ }^{1}$ Nicola Robinson ${ }^{2}$}

${ }^{1}$ Research Fellow, Faculty of Health and Social Care, London South Bank University, London, UK

${ }^{2}$ Professor of Traditional Chinese Medicine (TCM) and Integrated Health, Faculty of Health and Social Care, London South Bank University, London, UK

\section{Correspondence to:} Dr Ava Lorenc, Faculty of Health and Social Care, London South Bank University, 103 Borough Road, London SE1 OAA, UK; avalorenc@gmail.com

Received 23 June 2014 Revised 10 September 2014 Accepted 12 November 2014

\section{CrossMark}

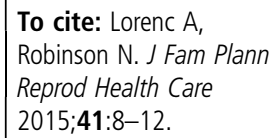

\section{BACKGROUND}

Patient and public engagement (PPE) consists of involving, consulting and listening to patients and the public, to make services responsive to patients' needs and improve clinical outcomes and patient experience. PPE has a central role in the UK National Health Service (NHS), at every level, from planning to delivery, including commissioning. ${ }^{1}$ NHS England state that "engaging and involving communities in the planning, design and delivery of health and care services can lead to more joined-up, co-ordinated and efficient services that are more responsive to local community needs". The 2012 Health and Social Care Act made PPE a legal duty for health care commissioners. $^{2}$ PPE supports NHS and government agendas to improve quality through new ideas and increasing patient empowerment, and can also reduce costs by providing and implementing services that patients want and will use, resulting in the reduction of unnecessary services. ${ }^{3}$ PPE can improve the patient experience, add value to services and support good governance, and co-production with patients can improve services ${ }^{3}{ }^{4}$ and clinical outcomes. ${ }^{1}$ A recent report entitled 'Changing Care, Improving Quality', developed by the Academy of Medical Royal Colleges, NHS Confederation and National Voices, discusses the need for 'reconfiguration' of NHS services and puts forward a case for patient engagement: ${ }^{3}$

\footnotetext{
"Where patients and their organisations are engaged from the start as equals in shaping the case for redesigning services, it is much more likely that reconfiguration will meet their needs and preferences and succeed in delivering better experience and outcomes."3
}

Absence of a culture of listening to patients can cause serious problems, as identified in a recent inquiry into a case of "appalling" NHS hospital care. ${ }^{5}$

PPE is particularly challenging in sexual and reproductive health and HIV/AIDS (SRHH) services due to stigma and confidentiality issues. ${ }^{6-8}$ Also, people at risk of poor SRHH are least likely to have their voices heard, particularly those from ethnic minorities, young people, sex workers, and those with mental illness, substance misuse problems and disabilities. ${ }^{9}$

Changes to UK health care services following the Health and Social Care Act 2012 divided the commissioning of SRHH services between: local authorities (as part of public health); clinical commissioning groups [CCGs: groups of general practitioners (GPs)]; and the National Commissioning Board. ${ }^{10}{ }^{11}$ Local authorities are responsible for some contraception, sexually transmitted infection testing and treatment, sexual health promotion and HIV prevention. ${ }^{12}$ They each have a Health and Wellbeing Board that is designed to integrate public health, social care and NHS services. ${ }^{12}$ The main role of CCGs in SRHH is commissioning abortion services. ${ }^{12}$ The National Commissioning Board takes on the commissioning of HIV treatment and care, and some contraceptive services. ${ }^{12}$ There was some concern that these changes may fragment the patient journey, and affect accountability and responsibility for PPE within services.

A range of resources and training on PPE is available for commissioners, for example:

- The Engagement Cycle, previously part of the NHS Institute for Innovation and Improvement. The Engagement Cycle is a tool for commissioners to "understand who needs to do what, in order to engage 
patients, communities and the public at each stage of commissioning", based on five stages and with simple advice for doing high-quality PPE at each stage. ${ }^{13}$

- NAZ Project London (a voluntary sector organisation for sexual health in Black and ethnic minority communities) have produced a report entitled 'Beyond Consultation', which suggests practical ways for commissioners to engage seldom-heard groups. ${ }^{14}$

- Guidance from NHS Employers on patient participation for commissioners of directed enhanced services, including step-by-step instructions and template materials. ${ }^{15}$

- Guidance on the National Institute for Health and Care Excellence (NICE) 'Patient Experience in Adult NHS Services' quality standard, which aims to provide guidance for commissioners on what is needed for a good patient experience. This is based on 14 'quality statements', with measures provided for each. ${ }^{16}$

- The NHS England document 'Planning and Delivering Service Changes for Patients', which is a good practice guide for commissioners on developing proposals for changes to services, including PPE. ${ }^{17}$

- 'Making it Work', a guide published for SRHH commissioners on whole systems commissioning, includes a brief section on the contribution PPE can make. ${ }^{11}$

However, very little of this is specific to SRHH and some has limited relevance for the new commissioning systems. With SRHH commissioned by both the NHS and local authorities, resources need to be appropriate for both these groups. For example, local authorities have a history of consulting with the local community, which is different to the NHS experience and is likely to influence how they do PPE.

The London Sexual Health Programme (LSHP) was established to support improvements in sexual health outcomes for Londoners by supporting and sharing best practice in commissioning. They identified the gap in guidance on PPE for commissioners of SRHH services and therefore commissioned a project to advise commissioners on current good practice in PPE in sexual and reproductive health. It was felt that a resource specifically designed for commissioners in the new structures was needed. In addition, NHS restructuring meant that many individuals would be moving jobs and some expertise around PPE might be lost, meaning a new resource was needed to ensure that standards did not drop.

We were therefore commissioned to design a training product for commissioners of SRHH services on PPE, and this article reports on the progress of its development. This was the second phase of a project funded by LSHP. The first phase is reported elsewhere $^{8} \quad 18$ and resulted in the development of a toolkit of PPE tools. 19

\section{METHODS EMPLOYED}

A steering group was set up to guide the project and provide expert input throughout the process. The group had representation from voluntary sector organisations, professional bodies and clinical services, as well as commissioners, patient representatives and clinicians. Members also consulted with the groups they represented, for example the British Association for Sexual Health and HIV (BASHH) Public Panel who commented on the plans. ${ }^{20}$ The group met three times over the course of the project.

The first stage of the project was a consultation with a variety of stakeholders to obtain their input into the product development. One of the authors (AL) met with stakeholders one-on-one to discuss their thoughts and experiences. Conversations were held with a range of individuals, identified by LSHP, including commissioners (NHS and local authority), clinicians, service managers, public health consultants and PPE leads. Specific topics discussed included previous experiences of PPE, hopes and fears for PPE, issues around PPE in SRHH, views on PPE in the new SRHH commissioning structures, PPE resources, and ideas and feedback regarding a training 'product' on PPE for commissioners.

Feedback from the consultation was then collated and discussed with the steering group to inform the product development. The product was developed based on these results, taken back to the steering group and further refined. A final draft version of the product was disseminated to the steering group and other stakeholders for comment before the launch of the final product in March 2013.

\section{STAKEHOLDER CONSULTATION RESULTS}

The results of the stakeholder consultation highlighted a number of themes to consider in developing the training product. PPE was seen as important in providing the right services, improving service access, being transparent/honest/accountable, prioritising spending, improving outcomes, and giving ownership and innovative ideas. Statutory duty and legislation were influential drivers and examples of policy drivers were given. PPE was also seen as useful for supporting cases to obtain funding for services. A range of examples of PPE were provided that were seen as helpful for shared learning about PPE and stimulating engagement. The changes to commissioning structures were frequently discussed. These changes and the transition process were anticipated to create fragmentation of services, unclear roles, but also opportunities for PPE. Many people thought that integration of services may improve PPE due to local authority expertise and exchange of information, with PPE remaining a core principle; however, people also felt that PPE may be affected by a lack of clarity, deprioritisation, lack of expertise and lack of trust from the public. Thus this time of change was seen as an opportunity for the training product to guide the future of PPE in the SRHH sector. Barriers to PPE included confidentiality, stigma, staff fear, organisational commitment, capacity, time, deprioritisation, cost and skills/ 
training. Measuring and monitoring PPE and its impact was limited. Individuals most commonly learnt about PPE from their organisation's PPE team and colleagues; no particular websites were used to inform PPE. Recommendations for our product included: an emphasis on how the product can help them achieve competencies/standards; making it a contractual obligation; integrating it into competencies; making it quick, easy, simple, enjoyable, with examples; and an online interactive tool hosted by LSHP.

As a result of these themes it was decided that the focus of the product should be on how commissioners can engage patients/public in the whole process of commissioning rather than simply being consulted on or engaged in one service. It was also clear that the product should emphasise proactive PPE rather than reactive one-off activities. The specific content was based on the themes identified from the consultation:

- The first instalment ('Getting in Shape') addressed the importance of PPE

- 'The Shape of Things to Come' explored opportunities for PPE in the new commissioning structures, and 'Shape Up' identified who will be responsible for PPE

- Overcoming stigma and engaging seldom-heard groups was addressed in 'Changing Shape'

- The emphasis on PPE being part of organisational structures was discussed in 'Shaping the Future'

- The importance of policy drivers and statutory duty were emphasised in two instalments ['Quality, Innovation, Productivity and Prevention (QIPP)-Shaped' and 'Ship Shape']

- Themes of how PPE can help to save money or prioritise spending were addressed in 'Get in Shape for Less'

- As measuring and monitoring PPE and its impact was seen to be limited, the final instalment 'Staying in Shape' focused on monitoring and evaluation of PPE.
Additional content was based on recommendations by the steering group:

- Working with the voluntary sector

- Linking SRHH to wider issues such as housing, finance and social policy.

Regarding the format, initially the steering group felt that the product should be face to face, perhaps an event or training course, or an e-learning course; however, this was not possible due to limited time and money. We also felt that the product needed to have a long-lasting influence and provide a reference source, rather than be a one-off event. Results of the consultation identified that an online product would be more useful and this was agreed at the second steering group meeting. Stakeholders in the consultation emphasised the need for the product to have some interactivity and to be targeted to individuals. We therefore decided on the 'blog' style format with instalments and direct email/social media updates to subscribers.

The final product, 'SHAPE' (Sexual Health And Public Engagement) is an online resource, consisting of 11 instalments on different topics (Figure 1), and a set of self-assessment questions. It is hosted on the LSHP website where anyone who is interested can subscribe to receive updates. ${ }^{21}$ Each time a new instalment was posted, an alert was sent to subscribers via RSS feed, twitter and email [using 'Mail Chimp' (mailchimp.com)]. Each instalment included a headline problem or issue, quotations from the consultation discussions (if the individual gave permission), followed by suggested solutions, examples of successes and links for further information, all in a downloadable PDF document. The instalments can be viewed on the LSHP website. ${ }^{21}$

Currently, the tool is endorsed by BASHH and the Royal College of Nursing, and has been advertised to

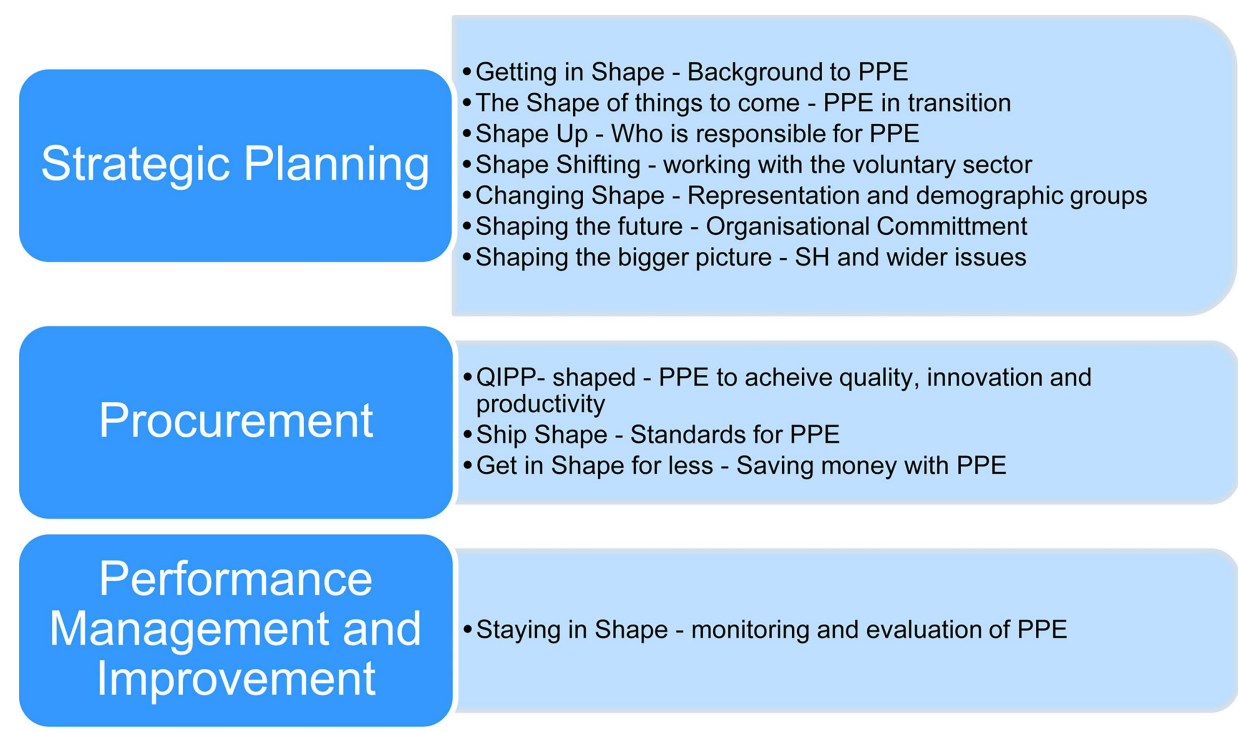

Figure 1 The 11 instalments of SHAPE. PPE, patient and public engagement; QIPP, Quality, Innovation, Productivity and Prevention; $\mathrm{SH}$, sexual health; SHAPE, Sexual Health And Public Engagement. 
clinical commissioning groups, NHS networks and LSHP mailing lists, and on the BASHH website. A presentation was given at a PPE Summit held in London in June 2013, attended by a range of voluntary sector and clinical organisations. A total of 33 individuals subscribed to SHAPE. We would welcome involvement from other interested groups, particularly in respect of hosting, endorsing or disseminating the product.

\section{DISCUSSION}

Over the lifetime of this project, and since SHAPE was created, there has been an increasing emphasis on PPE in the NHS, beginning to address concerns that the NHS is not committed as an organisation to PPE and that the NHS philosophy needs to change to create an 'ethos' of PPE. ${ }^{9} 2122$ The 2012 Health and Social Care $\mathrm{Act}^{2}$ has played a key part in these changes, putting a new legal duty on commissioners to engage, ${ }^{22}$ and a recent Public Health England guide for SRHH commissioners emphasises PPE. ${ }^{11}$ Concerns about patient care and safety, such as those outlined in the Francis Inquiry Report, have also prompted a reconsideration of the importance of good PPE. ${ }^{5}$ Along with guidance such as that from NHS England, ${ }^{1}$ these changes are a step in the right direction, but change will depend on local cultures and practices and individual decisionmakers' emphasis on PPE. ${ }^{22}$

However, there still remains a gap in practical guidance on the methods, processes and standards for PPE in the NHS. ${ }^{22} 23$ This project highlighted that this is particularly true for SRHH commissioners. The product created is, as far as we know, unique in addressing issues specific to SRHH PPE and targeting commissioners. We are keen for the issues raised in SHAPE to provide departure points for discussion and encourage further work.

We hope that reporting the process of developing the product is useful, particularly the consensus from stakeholders regarding the online format of the tool and the need for specific examples of PPE. Unfortunately we were unable to collect detailed data on use of the product beyond those who signed up for alerts. An evaluation of the product's use and usefulness would be an interesting future project. Similarly this project identified the need for evidence of successful PPE, including effectiveness and costs. ${ }^{22} 24$

This work was subject to some limitations, including limited financial resources and time. Dedicated budget and resources are needed to enable PPE. ${ }^{25}$ Due to limited resources we were unable to provide translators for those who could not speak English, which limits the generalisability of the findings, particularly given the burden of SRHH in hard-to-reach groups. Changes in commissioning of sexual health services from the Health and Social Care Act meant that primary care trusts, the funders of LSHP, were abolished, and so LSHP no longer exists. This affected the dissemination of the product, which was being led by LSHP. In addition, the success, use and implementation of the tool was challenged by the NHS reorganisation.

We feel that SHAPE addresses an important gap in the provision of resources and training on PPE and hope that it can help commissioners and others involved in patient care to ensure that patients and the public are genuinely engaged in the development and delivery of SRHH services.

Acknowledgements The authors would like to thank everyone who took part in the consultations. They are also very grateful to the members of the steering group who provided expert input into the design of the tool, including representatives from BASHH (British Association for Sexual Health and HIV), BPAS (British Pregnancy Advisory Service), patient representatives from Mortimer Market Centre (a GUM service in London), Panos London, NAZ Project London, Westminster PCT, Camden PCT, St George's Hospital NHS Trust, 56 Dean Street (Chelsea and Westminster Hospital), NELNET (North East London Sexual Health \& HIV Network), and the London Specialised Commissioning Group.

Funding The authors are grateful to the London Sexual Health Programme (LSHP) for funding their work.

Competing interests None.

Provenance and peer review Not commissioned; externally peer reviewed.

\section{REFERENCES}

1 NHS England. Transforming Participation in Health and Care. 2013. http://www.england.nhs.uk/wp-content/uploads/2013/09/ trans-part-hc-guid1.pdf [accessed 3 September 2014].

2 UK Government. Health and Social Care Act. 2012. http:// www.legislation.gov.uk/ukpga/2012/7/contents/enacted [accessed 3 September 2014].

3 The NHS Confederation, The Academy of Medical Royal Colleges, National Voices. Changing Care, Improving Quality. NHS Confederation. 2013. http://www.nhsconfed.org/ /media/ Confederation/Files/Publications/Documents/Changing-careimproving-quality.pdf [accessed 3 September 2014].

4 Tuke. Participative Medical Governance in the Delivery of Health Effective Medical Services. http://www.tukeinstitute.org [accessed 3 September 2014].

5 Francis R. Report of the Mid Staffordshire NHS Foundation Trust Public Inquiry: Executive Summary. 2013. http://www. midstaffspublicinquiry.com/sites/default/files/report/Executive\% 20summary.pdf [accessed 3 September 2014].

6 Medical Foundation for AIDs \& Sexual Health (MedFASH), British Association for Sexual Health and HIV (BASHH). Standards for the Management of Sexually Transmitted Infections (STIs). 2010. http://www.medfash.org.uk/uploads/ files/p17abk5ffh1d8f15amvq41dju1hnu5.pdf [accessed 3 September 2014].

7 House of Commons. Sexual Health. Third Report of Session 2002-2003. HC69. 2003. http://www.publications.parliament. $\mathrm{uk} / \mathrm{pa} / \mathrm{cm} 200203 / \mathrm{cmselect} / \mathrm{cmhealth} / 69 / 6905$.htm [accessed 3 September 2014].

8 Robinson N, Lorenc A. Strengthening the public voice in shaping sexual and reproductive health services - Changing relationships - PPE in Sexual and Reproductive Health and HIV/AIDS. 2010. http://www.londonsexualhealth.org/uploads/ 
Strengthening\%20Partnerships\%20FULL\%20REPORT.pdf [accessed 3 September 2014].

9 Involve and NHS National Centre for Involvement. Healthy Democracy: The Future of Involvement in Health and Social Care. 2007. http://www.wilsonielsen.com/wp-content/uploads/ 2011/05/Healthy-Democracy.pdf [accessed 3 September 2014].

10 London Sexual Health Programme (LSHP). Transition Guidance. http://www.londonsexualhealth.org/ transition-guidance.html [accessed 3 September 2014].

11 Public Health England. Making it Work: A Guide to Whole System Commissioning for Sexual Health, Reproductive Health and HIV. 2014. https://www.gov.uk/government/uploads/system/ uploads/attachment_data/file/351123/Making_it_work_FINAL_ full_report.pdf [accessed 3 September 2014].

12 Family Planning Association (fpa). What does the Health and Social Care Bill mean for sexual health services in England? 2012. http://www.fpa.org.uk/sites/default/files/health-andsocial-care-bill-and-sexual-health-services-march-2012.pdf [accessed 3 September 2014].

13 InHealth Ltd. The Engagement Cycle. http://engagementcycle. org/ [accessed 3 September 2014].

14 Panos London and NAZ Project London. Beyond Consultation: A Guide for Health Commissioners. How Staff and Service Users Can Work Together to Improve Health Services. 2012. http://panos.org.uk/wp-content/files/2012/03/BeyondConsultation-a-guide-for-health-commissioners.pdf [accessed 3 September 2014].

15 NHS England, NHS Employers, British Medical Association. Patient Participation Directed Enhanced Service (DES) for GMS Contract 2013/14. 2013. http://www.nhsemployers.org/ /media/Employers/Publications/2013_14_patient_ participation_DES_guidance.pdf [accessed 3 September 2014].

16 National Institute for Health and Care Excellence. Quality Standard for Patient Experience in Adult NHS Services. http:// www.nice.org.uk/guidance/qs15/chapter/introduction-andoverview [accessed 3 September 2014].
17 NHS England. Planning and Delivering Service Changes for Patients. 2013. http://www.england.nhs.uk/wp-content/uploads/ 2013/12/plan-del-serv-chge1.pdf [accessed 3 September 2014].

18 Robinson N, Lorenc A. 'No one wants to be the face of Herpes London': a qualitative study of the challenges of engaging patients and the public in sexual and reproductive health and HIV/AIDS services. Health Expect 2012. Published Online First: doi:10.1111/hex.12024.

19 London Sexual Health Programme (LSHP). The LSHP Toolkit. http://www.londonsexualhealth.org/patient-publicengagement/ppe-toolbox/the-toolkit.html [accessed 3 September 2014].

20 Clarke J, Chuter A. The BASHH public panel: climbing the ladder of involvement. Sex Transm Infect 2014;90:83.

21 London Sexual Health Programme (LSHP). SHAPE: Sexual Health and Public Engagement, a training tool for commissioners. 2013. http://www.londonsexualhealth.org/projects/patient-publicengagement/shape.html [accessed 3 September 2014].

22 Hudson B. Public and patient engagement in commissioning in the English NHS: an idea whose time has come? Public Management Review 2014. Published Online First: doi:10.1080/14719037.2014.881534.

23 Whitaker R. Participative Medical Governance in the Delivery of Health Effective Medical Services. 2010. http://www. tukeinstitute.org/Publications/Publications/CD_files/id-1004cd1.1.pdf [accessed 3 September 2014].

24 Pizzo E, Doyle C, Matthews R, et al. Patient and public involvement: how much do we spend and what are the benefits? Health Expect 2014. Published Online First. doi:10. 1111/hex.12204.

25 Medical Foundation for AIDs \& Sexual Health (MedFASH). Sex and Our City: Achieving Better Sexual Health Services for London, Project Findings \& Recommendations. 2008. http://www. medfash.org.uk/uploads/files/p17abkon9um3m1n1h4384ur75l. pdf [accessed 3 September 2014]. 